\title{
Fancy-Shaped Gold-Platinum Nanocauliflowers for Improved Proton Irradiation Effect on Colon Cancer Cells
}

\author{
Bartosz Klebowski $^{1}{ }^{\oplus}$, Joanna Depciuch ${ }^{1}{ }^{(0}$, Malgorzata Stec ${ }^{2}$, Dawid Krzempek ${ }^{1}{ }^{\circledR}$, \\ Wiktor Komenda ${ }^{1}$, Jarek Baran ${ }^{2, *(D)}$ and Magdalena Parlinska-Wojtan ${ }^{1, *(D)}$ \\ 1 Institute of Nuclear Physics Polish Academy of Sciences, 31-342 Krakow, Poland; \\ bartosz.klebowski@gmail.com (B.K.); joannadepciuch@gmail.com (J.D.); dawid.krzempek@ifj.edu.pl (D.K.); \\ wiktor.komenda@ifj.edu.pl (W.K.) \\ 2 Department of Clinical Immunology, Jagiellonian University Medical College, 30-663 Krakow, Poland; \\ malgorzata.stec@uj.edu.pl \\ * Correspondence: mibaran@cyf-kr.edu.pl (J.B.); magdalena.parlinska@ifj.edu.pl (M.P.-W.)
}

Received: 3 December 2020; Accepted: 15 December 2020; Published: 17 December 2020

\begin{abstract}
Enhancing the effectiveness of colorectal cancer treatment is highly desirable. Radiation-based anticancer therapy—such as proton therapy (PT)—can be used to shrink tumors before subsequent surgical intervention; therefore, improving the effectiveness of this treatment is crucial. The addition of noble metal nanoparticles (NPs), acting as radiosensitizers, increases the PT therapeutic effect. Thus, in this paper, the effect of novel, gold-platinum nanocauliflowers (AuPt NCs) on PT efficiency is determined. For this purpose, crystalline, 66-nm fancy shaped, bimetallic AuPt NCs were synthesized using green chemistry method. Then, physicochemical characterization of the obtained AuPt NCs by transmission electron microscopy (TEM), selected area electron diffraction (SAED), energy dispersive X-ray spectroscopy (EDS), and UV-Vis spectra measurements was carried out. Fully characterized AuPt NCs were placed into a cell culture of colon cancer cell lines (HCT116, SW480, and SW620) and a normal colon cell line (FHC) and subsequently subjected to proton irradiation with a total dose of $15 \mathrm{~Gy}$. The 3-(4,5-dimethylthiazol-2-yl)-5-(3-carboxymethoxyphenyl)-2-(4-sulfophenyl)-2H-tetrazolium (MTS) test, performed after 18-h incubation of the irradiated cell culture with AuPt NCs, showed a significant reduction in cancer cell viability compared to normal cells. Thus, the radio-enhancing features of AuPt NCs indicate their potential application for the improvement in effectiveness of anticancer proton therapy.
\end{abstract}

Keywords: gold-platinum nanocauliflowers; radiosensitizers; proton therapy; MTS test; transmission electron microscopy; green chemistry; gallic acid

\section{Introduction}

Malignant tumors are civilization-related diseases that more and more people suffer from every year worldwide. Among them, colorectal cancer is the third most common, and this type of cancer can be successfully cured at its early stage by surgical treatment [1]. Unfortunately, at more advanced stages, other methods such as radiation or chemotherapy alone or in combination with immunotherapy are recommended; however, their effectiveness is still limited [2-4]. Radiation-based anticancer therapy, such as proton radiotherapy, can be used in selective cases, especially before surgery (along with chemotherapy), to help shrink a tumor and to make it easier to remove or to enhance the effectiveness of immunotherapy $[5,6]$. The application of a proton beam enables precise irradiation of the tumor and, thus, saving normal tissues [7]. However, it is worth noting that the method of proton delivery 
(and at the same time, the precision of irradiation) depends on the region of the Bragg curve that is used for tumor irradiation. In the case of the Plateau region, an approximately constant value of relative biological effectiveness $(\mathrm{RBE})=1.1$ is obtained. On the other hand, in the case of a Bragg peak, we get a high, rapidly changing RBE, making it difficult to determine the actual radiation dose [8]. In this regard, it is highly advisable to find a new tool, which will improve this type of neoadjuvant therapies. The help comes to us with so-called radiosensitizers [9].

Radiosensitizers, being low in toxicity, significantly improve the efficiency of radiation-based anticancer therapies such as X-ray radiation-, proton-, or photodynamic therapy [10-12]. Radiosensitizers are divided into several types: small molecular chemotherapeutics (e.g., gemcitabine), macromolecules (microRNA and proteins), or nanoparticles (NPs) [13]. The aforementioned radiosensitizers are aimed at improving the effectiveness of, e.g., proton therapy (PT), while reducing its side effects because the radiation dose used in this case can be much lower [14]. Currently, the application of NPs, especially noble metal NPs, for this purpose is highly promising.

Nanomedicine deals with the use of sub-micrometer materials not only as radiosensitizers but also as drug delivery systems or contrast agents in medicine [15]. It is associated with a number of undoubted advantages of such nanomaterials, which include their small size, large surface area, and stability $[16,17]$. Noble metal NPs, especially gold nanoparticles (Au NPs), which have fascinating abilities, ought to be highlighted in a special way. Their capacity for enhancement of photoelectric interaction at lower energy levels as well as the possibility of increasing the energy deposited in the tumor deserves attention [18]. Under the influence of the proton beam, Au NPs (and other high atomic number NPs) generate reactive oxygen species (ROS) and free radicals which are destructive to deoxyribonucleic acid (DNA), causing its breakage and, thus, cell death [12,19-24]. A similar effect, however with different powers, can be seen for other types of noble metal NPs, e.g., platinum (Pt NPs), gadolinium (Gd NPs), and silver (Ag NPs) $[9,12]$.

The aim of this study was to establish the synthesis of novel, fancy-shaped bimetallic gold-platinum nanocauliflowers (AuPt NCs) with a highly developed surface area. This is of interest because there is limited information about the application of bimetallic NPs to support the effect of proton irradiation. AuPt NCs were prepared using a green chemistry, eco-friendly method, applying gallic acid as a "green" reducing agent.

In this paper, we examined the radio-sensitizing effect of bimetallic 66-nm AuPt NCs on three cancer cell lines with different malignancy: HCT116, SW480, and SW620 as well as the normal colon cell line FHC. The efficiency of the PT supported by AuPt NCs was investigated by a cytotoxicity 3-(4,5-dimethylthiazol-2-yl)-5-(3-carboxymethoxyphenyl)-2-(4-sulfophenyl)-2H-tetrazolium (MTS) assay. Physicochemical characterization of AuPt NCs was also carried out. Transmission electron microscopy (TEM) served to assess the morphology of the obtained AuPt NCs. The chemical composition of as-prepared AuPt NCs was analyzed by energy dispersive X-ray spectroscopy (EDS). Selected area electron diffraction (SAED) was used to examine the crystal structure of AuPt NCs. The UV-Vis spectrum was also measured. An overview scheme of the investigation procedure is presented in Figure 1. 


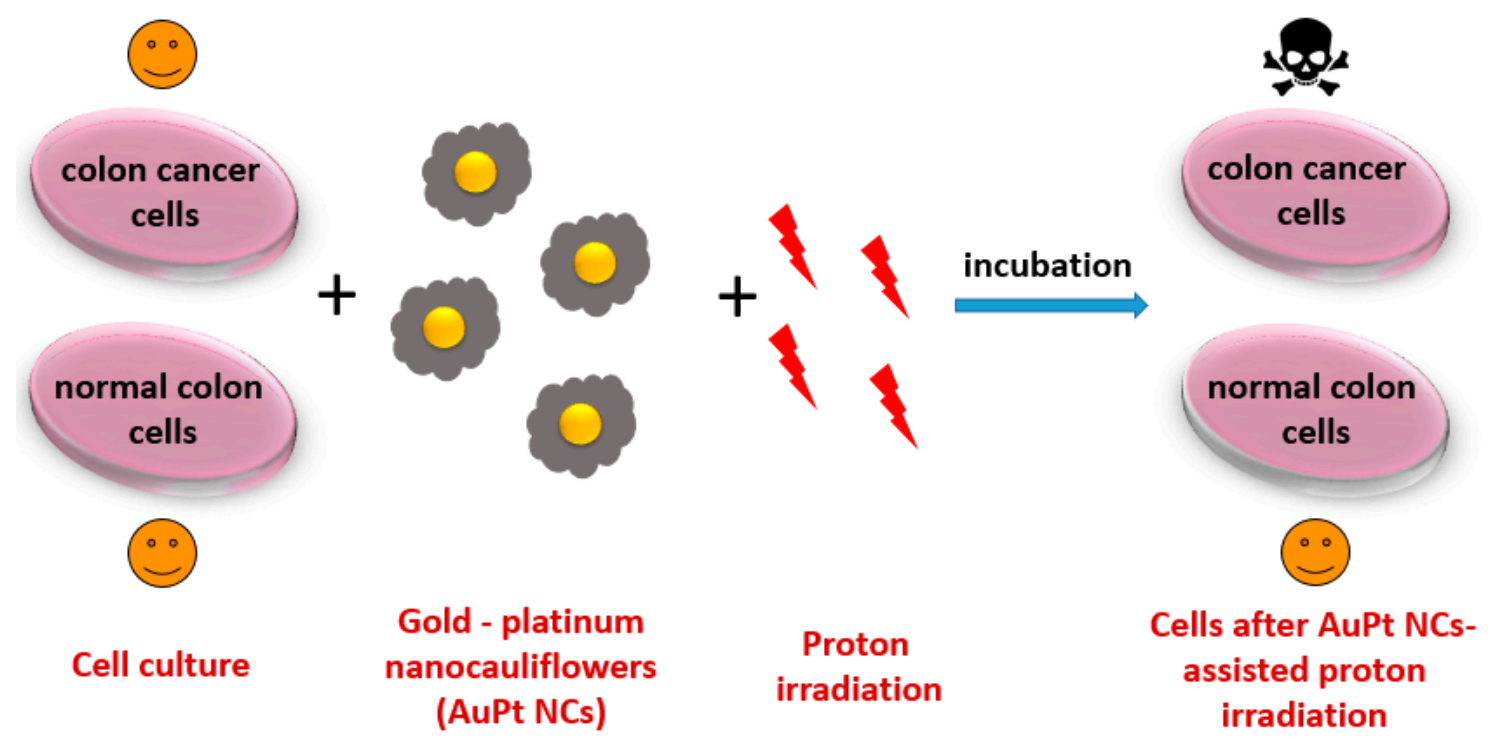

Figure 1. Overview scheme of the investigation procedure.

\section{Results and Discussion}

\subsection{Mechanism of AuPt NCs (Gold-Platinum Nanocauliflowers) Synthesis}

In the studies presented, we obtained gold-platinum NPs with a novel shape resembling cauliflowers. They were prepared by chemical reduction of gold and platinum $\left(\mathrm{HAuCl}_{4}\right.$ and $\mathrm{H}_{2} \mathrm{PtCl}_{6}$, respectively) precursors using gallic acid, which is both a reducing agent and a stabilizer preventing agglomeration of these NPs. Gallic acid, being an environmentally friendly "green" reagent, is also relatively cheap. Moreover, gallic acid exhibits a broad spectrum of activity when it comes to reducing various metal precursors, which allows it to be used in the synthesis of numerous monometallic NPs as well as multicomponent nanocomplexes [25-29]. By controlling the reaction parameters (e.g., temperature or polyvinylpyrrolidone addition), it is possible to obtain nanoparticles with various sizes [30]. Such reducing properties of gallic acid are due to the fact that it consists of an aromatic ring containing a carboxyl and hydroxyl group. These groups form chelating rings with metal ions, which are oxidized to benzoquinones by exposure to air or electrophilic ions [31].

The proposed reaction mechanism of the AuPt NCs synthesis is presented in Figure 2.

A color change of the solution to brown was observed directly after the addition of gallic acid to the reaction mixture containing gold and platinum precursors. The very fast formation of $\mathrm{AuPt}$ NCs was due to the significant difference in standard redox potentials of the two metal precursors [30]. The individual ions were reduced to the corresponding metals according to the reactions presented in Figure 2. In turn, gallic acid was transformed into its oxidized form [32]. This reaction took place in two steps, which proceed very quickly one after the other. In the first step, gallic acid reduced gold ions, as they have a higher standard redox potential. Thus, Au NPs were formed as cores on which the platinum nanoparticles (Pt NPs) could later be deposited. The second stage of AuPt NC synthesis consisted of two-stage reduction of platinum ions-initially to $\left[\mathrm{PtCl}_{4}\right]^{2-}$ ions and finally to metallic platinum, which was deposited on the nanogold surface. It is worth noticing that, due to the fact that these reactions took place almost simultaneously, only the final brown color corresponding to AuPt NCs was observed in the reaction mixture. On the other hand, we did not observe the red color of the solution corresponding to formation of Au NPs with a size of about $20 \mathrm{~nm}$ [33]. The formation of a porous platinum shell was ensured by the addition of excess platinum precursors to the reaction mixture. 


\section{Progress of the gold - platinum nanocauliflowers synthesis} using gallic acid as reducing agent

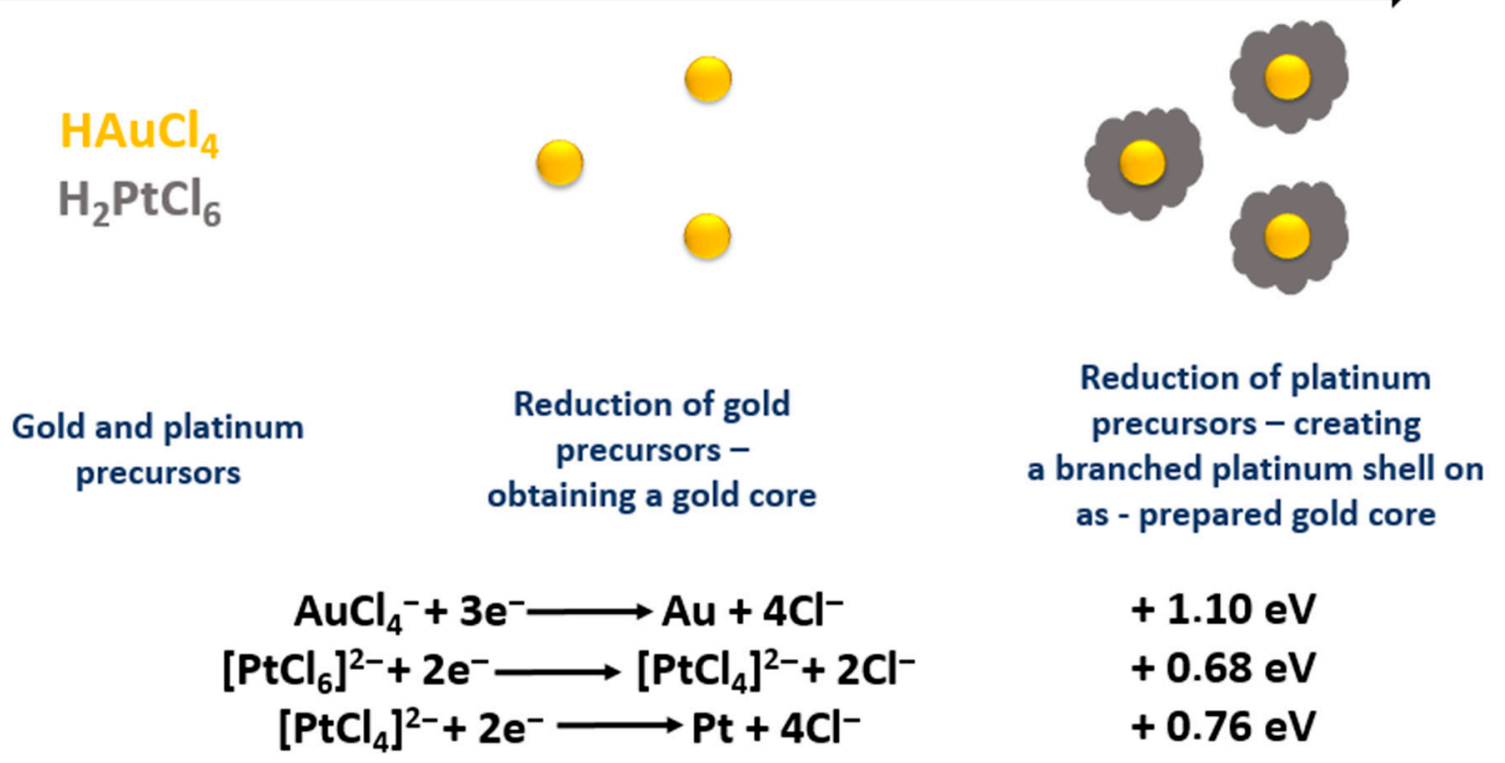

Figure 2. Synthesis mechanism of AuPt nanocauliflowers (NCs) using gallic acid.

\subsection{Physicochemical Characterization of AuPt NCS}

Several techniques were used to fully characterize the obtained AuPt NCs. The morphology, chemical composition, and microstructure of AuPt NCs were determined by scanning transmission electron microscopy (STEM) with the High-angle annular dark-field detector (HAADF) detector, energy dispersive X-ray spectroscopy (EDS) maps, and the SAED patterns taken in the TEM mode (Figure 3a-d). Based on the STEM images, the size distribution of AuPt NCs was estimated (Figure 3e).

Reduction of gold and platinum precursors using gallic acid resulted in preparation of monodisperse AuPt NCs with an average size of $66 \mathrm{~nm}$ (Figure 3e). The size of the gold core was estimated to be around $20 \mathrm{~nm}$. The shape of both Au NPs and Pt NPs was spherical. We observed that the platinum shell was composed of small, less than $5 \mathrm{~nm}$ Pt NPs agglomerated into larger nanostructures. On the STEM image (Figure 3a) and corresponding EDS map of AuPt NCs (Figure 3b, Figure S1), we noted the presence-in addition to AuPt NCs—of agglomerated Pt NPs consisting of smaller, approximately $2 \mathrm{~nm}$ Pt NPs without a gold core. These Pt NPs had weaker contrast due to the lower $\mathrm{Z}$ atomic number of platinum $(\mathrm{Z}=78)$ than gold $(\mathrm{Z}=79)$.

From the SAED pattern, it was found that the obtained AuPt NCs have a crystalline structure (sharp diffraction rings with bright spots were observed). The diffraction rings (Figure 3d) could be attributed to the (111), (200), (220), and (311) lattice planes of Au and Pt nanocrystals crystalized in the face-centered cubic structure [34].

The UV-Vis measurements of AuPt NCs were also carried out (Figure 4). We did not detect any peak in the analyzed spectral range. Spherical Au NPs should have given an absorption peak in the visible light spectrum; however, we did not observe it [35]. This proved that the nanogold core was completely covered with Pt NPs, for which there was no absorption peak in the UV-Vis range [36]. Absence of any other peaks in this wavelength range indicated a lack of sample contamination. 

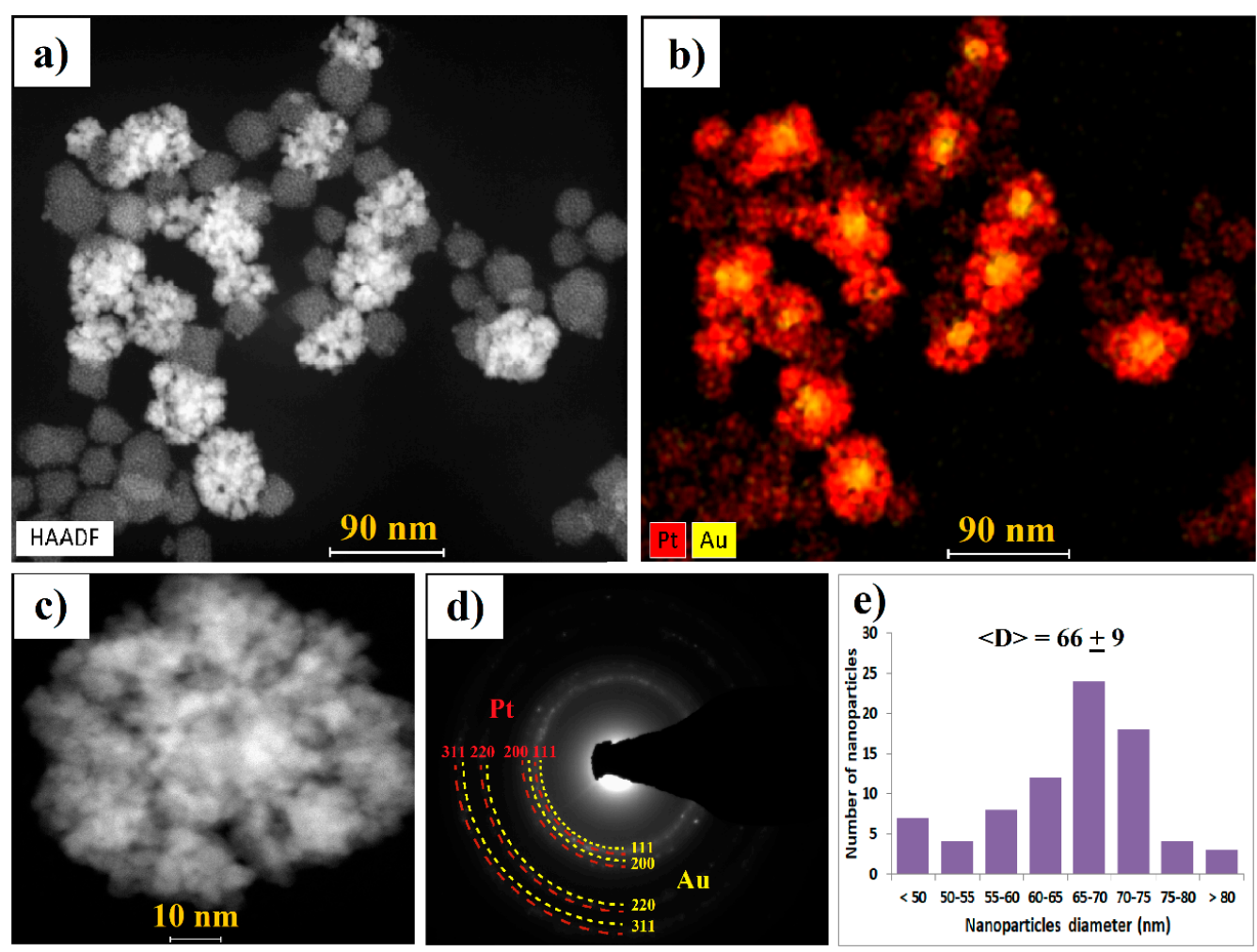

Figure 3. Morphology of AuPt NCs: (a) scanning transmission electron microscopy (STEM) High-angle annular dark-field detector (HAADF) overview image, (b) energy dispersive X-ray spectroscopy (EDS) distribution map of gold (yellow) and platinum (red) in AuPt NCs, (c) STEM HAADF higher magnification image, (d) corresponding selected area electron diffraction (SAED) pattern, and (e) size distribution of AuPt NCs.

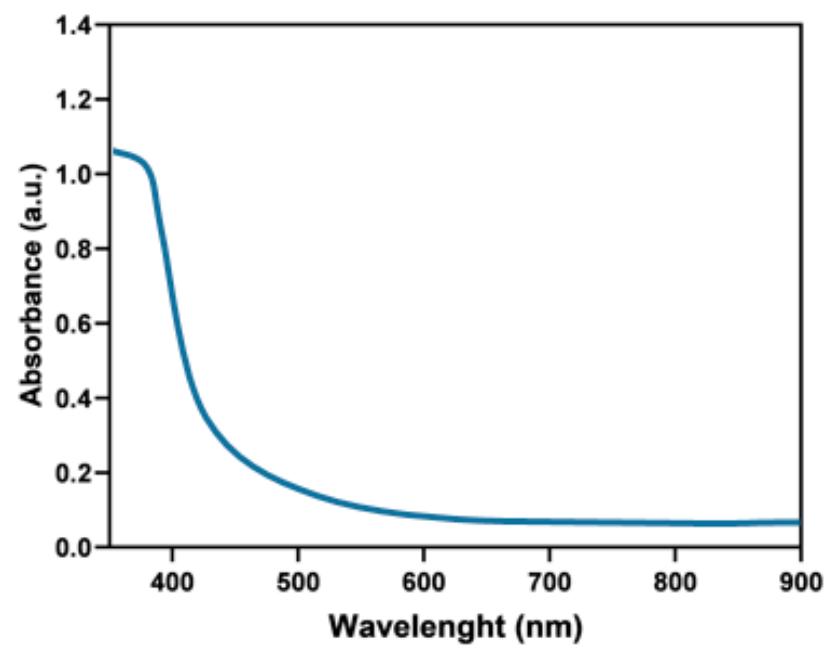

Figure 4. UV-Vis spectrum of AuPt NCs.

\subsection{Impact of AuPt NCs on Enhancement of the Proton Beam Irradiation Effect for Selected Cell Lines}

The changes in the colon cancer and normal epithelium cells' viability caused by AuPt NCs as well as by AuPt NC-assisted proton bream irradiation were determined using the MTS assay. The description of all the samples analyzed in this experiment is shown in Table 1.

Firstly, the cytotoxicity of AuPt NCs was determined. For this purpose, different concentrations of AuPt NCs were used in the cultures with cancer or normal cells at three different incubation times. The obtained results are presented in Figure 5. 
Table 1. Description of the investigated samples.

\begin{tabular}{cc}
\hline Sample & Name of Sample in the Manuscript \\
\hline $\begin{array}{c}\text { SW480, SW620, HCT116, and FHC cells without addition of AuPt } \\
\text { nanocauliflowers (NCs) and proton irradiation (controls) }\end{array}$ & Ctrl \\
\hline Cells cultured with AuPt (NCs) & C@AuPt NCs \\
\hline Cells irradiated by proton beam & $\mathrm{C} @ P R^{+}$ \\
\hline Cells cultured with AuPt NCs and irradiated by proton beam & $\mathrm{C@AuPt} \mathrm{NCs@PR}$ \\
\hline
\end{tabular}

The highest cytotoxicity of NCs-for all three incubation times-was noticed for the SW480 primary cancer cells. This is consistent with other reports-SW480 cells are generally more sensitive to some NPs or drugs than the SW620 or HCT116 cells [37-39]. The cytotoxicity of NPs depends not only on the metals used but also on their size, shape, or synthesis method [40,41]. Different concentrations of AuPt NCs were chosen for AuPt NC-assisted proton irradiation: $50 \mu \mathrm{L} / \mathrm{mL}$ for SW480 and $75 \mu \mathrm{L} / \mathrm{mL}$ for SW620 and HCT116 cells, respectively. These concentrations were considered as not causing a significant decrease in viability of these cells, i.e., less than $15 \%$ of cells were dead. Moreover, normal FHC cells were treated with both AuPt NCs concentrations to reliably compare the proton irradiation effect on the cancer and normal cells. There was no difference in cell viability for the 18 and $24 \mathrm{~h}$ incubation times, so further studies were carried out for $18 \mathrm{~h}$ of incubation of NPs with cells. It should be also mentioned that before AuPt NCs addition to the cell culture, the number of cells in the Burker chamber was counted to ensure approximately the same NP-cell ratios for all investigated cell lines.

In the next step, the effectiveness of AuPt NC-supported proton beam irradiation with a total irradiation dose of $15 \mathrm{~Gy}$ and $18 \mathrm{~h}$ incubation time after irradiation was investigated. The results are shown in Figure 6. The highest decrease in cell viability (93\%) after irradiation with the proton beam (without the addition of AuPt NCs) was observed for the SW620 cells. In turn, FHC cells were less radiosensitive than both types of colon cancer cells, which is in line with the literature [42]. AuPt NC-assisted proton beam therapy turned out to be more effective than proton radiotherapy without the presence of NPs. It was observed that the addition of AuPt NCs, with a concentration which does not decrease cell viability by more than $15 \%$, to the cell culture, significantly enhances the effect of irradiating cells with protons (Figure 6a-c). The highly developed surface of this type of bimetallic NP ensures large contact area of the cells with AuPt NCs, which results in generation of an increased amount of ROS destructive to cancer cells. A similar effect was observed when using porous Pt NPs as radiosensitizers in this type of anticancer therapy [43]. In Figure 6, statistically significant differences between the C@AuPt NCs@PR ${ }^{+}$and Ctrl were observed. The addition of AuPt NCs to the cell culture followed by proton irradiation resulted in a mortality of approximately $16 \%, 26 \%, 38 \%$, and $41 \%$ for FHC, HCT116, SW480, and SW620 cells, respectively. Among all studied cancer cell lines, the HCT116 cells are characterized by the lowest sensitivity to AuPt NC-assisted proton irradiation, which is confirmed by previous reports on the high malignance/metastasis potential of this cell line [44,45]. Moreover, there was a significant statistical difference in viability between normal FHC cells and cancer cells irradiated with protons and cultured with the same concentration of AuPt NCs. The negligible influence of this type of combined therapy on the normal cells is highly desirable from a therapeutic point of view. The presence of gallic acid, being a stabilizer of AuPt NCs, may influence such a selective action of this type of therapy on cancer. This compound has anti-inflammatory, antiallergic, antibacterial, and anticancer properties [32,46,47]. Several studies have shown that gallic acid has a selectively toxic effect on cancer cells, while saving normal ones [48-50]. Improving the selectivity of NPs towards cancer cells is particularly important for application of these nanomaterials in the clinic. For this purpose, it is desirable to biofunctionalize such NPs with some compounds increasing the cellular uptake by cancer cells. In the literature, there are reports on modification of nanoparticles with proteins (e.g., albumin) or tumor-specific antibodies, e.g., anti-Her2/neu or anti-epidermal growth factor receptor (EGFR) [51,52]. 

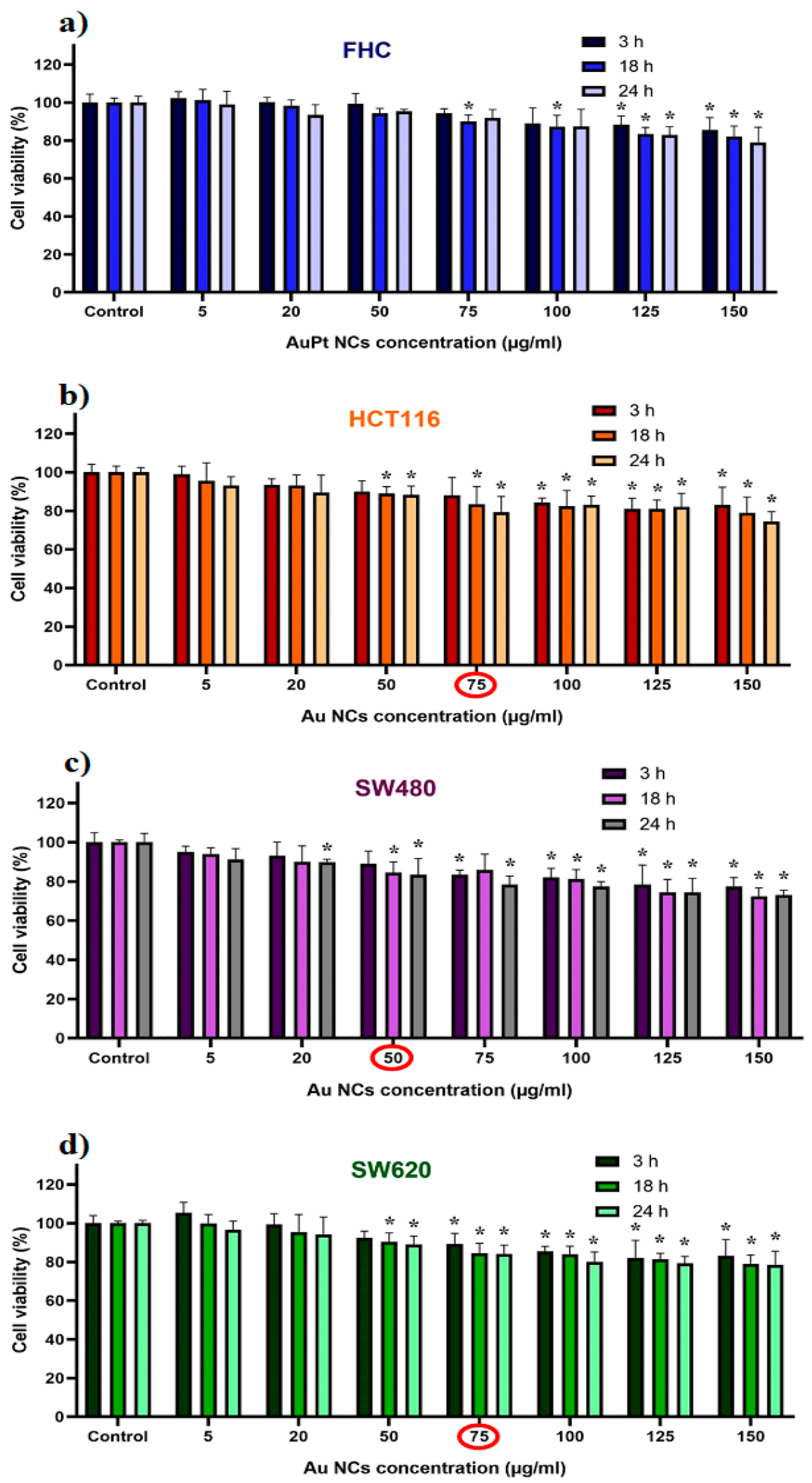

Figure 5. Cytotoxicity of AuPt NCs against (a) FHC, (b) HCT116, (c) SW480, and (d) SW620 cells after 3,18 , and $24 \mathrm{~h}$ of incubation: data were considered significant when ${ }^{*} p<0.05$ versus control. The concentrations of HCT116, SW480, and SW620 cells considered optimal were marked in red. 

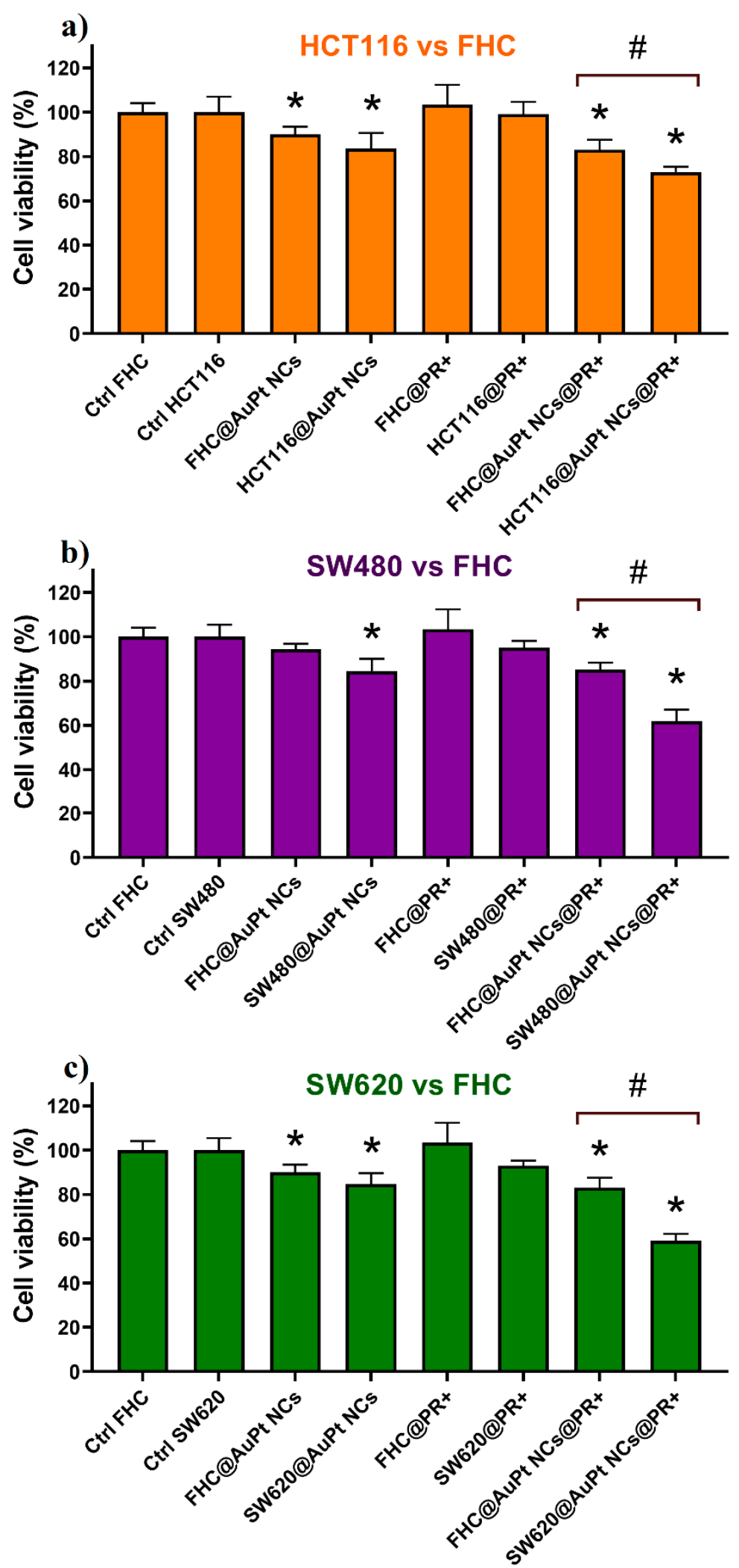

Figure 6. Viability of (a) HCT116, (b) SW480, and (c) SW620 cancer cells compared to FHC normal cells after the addition of AuPt NCs and proton irradiation of a total dose of 15 Gy combined with AuPt NCs: data were considered significant if * $p<0.05$ versus control; $\# p<0.05$-statistically significant differences between the respective cancer line and the normal line. 
Summarizing, the results of our research indicate the high application potential of AuPt NCs in proton beam irradiation of human cancer. Further progress in this area may allow access to an effective tool to support also other radiation-based anticancer therapies, e.g., photon- or photodynamic therapy.

\section{Materials and Methods}

\subsection{Reagents and Chemicals}

Hydrogen tetrachloroaurate trihydrate $\left(\mathrm{HAuCl}_{4} \times 3 \mathrm{H}_{2} \mathrm{O}\right)$, hydrogen hexachloroplatinate hexahydrate $\left(\mathrm{H}_{2} \mathrm{PtCl}_{6} \times 6 \mathrm{H}_{2} \mathrm{O}\right)$, and gallic acid were purchased from Sigma-Aldrich (Saint Louis, $\mathrm{MO}$, USA). Chemical reagents were used without additional purification or modification.

\subsection{AuPt NCs Synthesis}

AuPt NCs were synthesized by green chemistry method using gallic acid acting simultaneously as a stabilizer and reducing agent. One hundred $\mu \mathrm{L}$ of $\mathrm{HAuCl}_{4}$ and $400 \mu \mathrm{L}$ of $\mathrm{H}_{2} \mathrm{PtCl}_{6}$ aqueous solutions $\left(10^{-2} \mathrm{M}\right)$ were mixed in $17.5 \mathrm{~mL}$ distilled water in a round-bottom flask. The reaction mixture was heated until boiling on a magnetic stirrer (300 rpm), and then $2 \mathrm{~mL}$ of $5 \times 10^{-3} \mathrm{M}$ freshly prepared gallic acid solution was added. The reaction was carried out for $30 \mathrm{~min}$, observing color change of the solution from colorless to brown, which indicates the formation of AuPt NCs.

\subsection{TEM Characterization}

Scanning transmission electron microscopy (STEM) combined with the high-angle annular dark-field detector (HAADF) working in conventional and high-resolution mode served as a tool to evaluate the morphology of prepared AuPt NCs. SAED patterns were taken in the TEM mode. All these measurements were performed on an aberration-corrected FEI Titan electron microscope operating at $300 \mathrm{kV}$ equipped with an FEG (field emission gun) cathode. EDS mappings were done using a FEI Talos TEM operating at $200 \mathrm{kV}$ equipped with an FEG cathode and four in-column EDS detectors (Super EDS system) The particle size distribution was evaluated based on STEM images taken from different areas of the TEM grids, which showed that the morphology of the AuPt NCs is the same in the whole analyzed sample (Figure S2). The AuPt NCs were measured and analyzed using TIA Software. The diameter of about $100 \mathrm{AuPt}$ NCs was measured as a distance between the two most distant points of these NPs.

\subsection{UV-Vis Spectroscopy}

The UV-Vis measurements were performed using a UV-2600 instrument from Shimadzu. The resolution was chosen to be $1 \mathrm{~nm}$, and the sampling interval was 1 . The volume of each sample was $1 \mathrm{~mL}$. The spectral range was from $200 \mathrm{~nm}$ to $900 \mathrm{~nm}$.

\subsection{Cell Culture}

Colon cancer cell lines (SW480 and SW62) were obtained due to the courtesy of Prof. Caroline Dive, Paterson Institute for Cancer Research, University of Manchester. Human colon carcinoma cell line HCT116 and fetal colon cell line FHC (CRL-1831) were obtained from the American Type Culture Collection (ATCC, Manassas, VA, USA) and maintained according to the ATCC's instructions. HCT116 cells were cultured in McCoy's 5A medium (Gibco, Paisley, UK). SW480 and SW620 cells were cultured in DMEM (Dulbecco's modified eagle medium) with high glucose (Corning, NY, USA). FHC cells were cultured in DMEM/F12 medium (Gibco) supplemented with 25 mM HEPES (4-(2-hydroxyethyl)-1-piperazineethanesulfonic acid), $10 \mathrm{ng} / \mathrm{mL}$ cholera toxin, $0.005 \mathrm{mg} / \mathrm{mL}$ insulin, $0.005 \mathrm{mg} / \mathrm{mL}$ transferrin, and $100 \mathrm{ng} / \mathrm{mL}$ hydrocortisone. All media were supplemented with $10 \%$ fetal bovine serum (FBS, Gibco) and ciprofloxacin $(10 \mu \mathrm{g} / \mathrm{mL})$. The cells were cultured by biweekly passages in a $37^{\circ} \mathrm{C}$ humidified atmosphere with $5 \% \mathrm{CO}_{2}$ and regularly tested for Mycoplasma sp. contamination. 


\subsection{Proton Irradiation and Dosimetry}

Irradiations were performed in the Cyclotron Centre Bronowice, Institute of Nuclear Physics Polish Academy of Sciences, Krakow, Poland. The proton therapy system was installed in the Centre consists of a IBA proteus C-235 cyclotron (IBA PT, Louvain-la-Neuve, Belgium) and two gantries equipped with scanning nozzles. In pencil beam scanning (PBS) techniques, a narrow proton beam is deflected in two perpendicular directions, delivering the dose point by point to the whole target volume. Irradiations were performed using a monoenergetic field with an energy of $225 \mathrm{MeV}$ and dimensions of $20 \mathrm{~cm} \times 20 \mathrm{~cm}$. The cells were irradiated at $1.1 \mathrm{~cm}$ water equivalent depth with a dose of $15 \mathrm{~Gy}$. The gantry was set at $180^{\circ}$, meaning that the beam was directed from the bottom to the top. The preparation of the experiment included dosimetry measurements performed with a Markus type ionization chamber calibrated in terms of dose absorbed to water. A radiation dose of 15 Gy was experimentally selected for our research as nontoxic to the cell lines used. After proton irradiation, each cell line was incubated for $18 \mathrm{~h}$ and then cell viability was assessed by MTS assay.

\subsection{MTS Viability Assay}

Cytotoxic activity of AuPt NCs against normal and cancer cells was determined using 3-(4,5-dimethylthiazol-2-yl)-5-(3-carboxymethoxyphenyl)-2-(4-sulfophenyl)-2H-tetrazolium (MTS) assay (CellTiter $96^{\circledR}$ Aqueous One Solution Cell Proliferation Assay, Promega, Madison, WI). Briefly, the cells were cultured in flat-bottom 96-well plates (Sarstedt, Numbrecht, Germany) at a density of $1 \times 104 /$ well in DMEM medium containing $10 \%$ FBS. After $48 \mathrm{~h}, 20 \mu \mathrm{L}$ of AuPt NC solutions with different concentrations was added to the $100 \mu \mathrm{L}$ medium with cells, giving a final concentration of AuPt NCs in the medium in the range between 5-150 $\mu \mathrm{g} / \mathrm{mL}$. After incubation periods of 3, 18, and $24 \mathrm{~h}$, $20 \mu \mathrm{L}$ of MTS dye solution was added per well. The quantity of formazan product, directly proportional to the number of living cells in culture, was detected by absorbance measurements at $490 \mathrm{~nm}$ with a 96-well plate reader (Spark ${ }^{\circledR}$ Tecan, Mannedorf, Switzerland). For further AuPt NC-assisted proton irradiation studies, a maximum concentration which did not cause a decrease in cell survival by more than $15 \%$ after $18 \mathrm{~h}$ incubation was selected $(50 \mu \mathrm{g} / \mathrm{mL}$ for SW 480 and $75 \mu \mathrm{g} / \mathrm{mL}$ for SW620 and HCT116 cells). As for the FHC cell line (control), these cells were treated with both (50 and $75 \mu \mathrm{g} / \mathrm{mL}$ ) AuPt NC concentrations allowing reliable comparison of the effect of proton irradiation on normal and colon cancer cells.

\subsection{Statistical Analysis of Cell Viability Data}

The obtained MTS assay results are represented as the means \pm SEM (standard error of the mean). The experimental data were analyzed by one-way analysis of variance (ANOVA) followed by post hoc Tukey test. $p$ value $<0.05$ was considered statistically significant. The data were analyzed and presented graphically using GraphPad Prism 8 Software.

\section{Conclusions}

In this work, we have shown a synergistic effect of $66 \mathrm{~nm} \mathrm{AuPt} \mathrm{NCs} \mathrm{and} \mathrm{proton} \mathrm{irradiation} \mathrm{towards}$ the destruction of colon cancer cells. Synthesized by green chemistry and fully characterized by physicochemical methods, AuPt NCs showed a highly developed active surface, which allowed them to have a larger contact area with the cells. This fact as well as the presence of gallic acid- having strong anticancer properties-in the structure of AuPt NCs gave promising results. AuPt NC-assisted proton irradiation proved to be particularly effective in killing cancer cells (especially in SW480 and SW620 colon cancer cells, where a decrease in survival to approximately $60 \%$ was observed), while normal cells were only slightly affected (viability $>80 \%$ ). Moreover, the application of green chemistry reagents for the production of NPs is favorable for ecology and ensures higher biocompatibility of such nanomaterials. Thus, the development of new and the improvement of already known metallic NPs in the future may contribute to finding the "golden mean" in the fight against various types of cancers. 
Supplementary Materials: The following are available online at http://www.mdpi.com/1422-0067/21/24/9610/s1, Figure S1: (A) STEM higher magnification image of AuPt NCs, EDS distribution maps of: (B) gold and platinum in the AuPt NCs, (C) gold (yellow) and (D) platinum (red), separately, Figure S2: Determination of the size of AuPt NCs as the distance between two extreme points of these NPs based on STEM HAADF images.

Author Contributions: Conceptualization, B.K., J.D., and M.P.-W.; methodology, B.K., J.D., M.S., D.K., W.K., and M.P.-W.; validation, B.K.; formal analysis, B.K.; writing—original draft preparation, B.K.; writing-review and editing, J.B., M.P.-W., and J.D.; supervision, J.B. and M.P.-W.; funding acquisition, J.B. All authors have read and agreed to the published version of the manuscript.

Funding: The APC was funded by the European Commission H2020-MSCA-RISE-2017 Project "CANCER" (GA no. 777682).

Acknowledgments: The authors thank the Institute of Engineering Materials and Biomaterials of the Silesian University of Technology for the use of the Titan FEI TEM instrument. The study was carried out with the Talos F200 FEI TEM equipment purchased by Biological and Chemical Research Centre, University of Warsaw, established within the project cofinanced by the European Union from the European Regional Development Fund under the Operational Program Innovative Economy, 2007-2013. B.K. acknowledges support of the InterDokMed project no. POWR.03.02.00-00-I013/16.

Conflicts of Interest: The authors declare no conflict of interest.

\section{Abbreviations}

$\begin{array}{ll}\text { Ag NPs } & \text { Silver nanoparticles } \\ \text { AuPt NCs } & \text { Gold-platinum nanocauliflowers } \\ \text { DMEM } & \text { Dulbecco's modified eagle medium } \\ \text { EDS } & \text { Energy dispersive X-ray spectroscopy } \\ \text { EGFR } & \text { Epidermal growth factor receptor } \\ \text { FBS } & \text { Fetal bovine serum } \\ \text { FEG } & \text { Field emission gun } \\ \text { Gd NPs } & \text { Gadolinium nanoparticles } \\ \text { HAADF } & \text { High-angle annular dark-field detector } \\ \text { HEPES } & \text { 4-(2-hydroxyethyl)-1-piperazineethanesulfonic acid } \\ \text { MTS } & \text { 3-(4,5-dimethylthiazol-2-yl)-5-(3-carboxymethoxyphenyl)-2-(4-sulfophenyl)-2H-tetrazolium } \\ \text { PBS } & \text { Pencil beam scanning } \\ \text { PT } & \text { Proton therapy } \\ \text { Pt NPs } & \text { Platinum nanoparticles } \\ \text { RBE } & \text { Relative biological effectiveness } \\ \text { ROS } & \text { Reactive oxygen species } \\ \text { SAED } & \text { Selected area electron diffraction } \\ \text { STEM } & \text { Scanning transmission electron microscopy }\end{array}$

\section{References}

1. Colorectal Cancer Statistics. Colorectal Cancer Is the Third Most Common Cancer Worldwide. Available online: https://www.wcrf.org/dietandcancer/cancer-trends/colorectal-cancer-statisticsl (accessed on 10 September 2020).

2. Ji, D.; Zhan, T.; Li, M.; Yao, Y.; Jia, J.; Yi, H.; Qiao, M.; Xia, J.; Zhang, Z.; Ding, H.; et al. Enhancement of sensitivity to chemo/radiation therapy by using miR-15b against DCLK1 in colorectal cancer. Stem Cell Rep. 2018, 11, 1506-1522. [CrossRef]

3. Geng, L.; Wang, J. Molecular effectors of radiation resistance in colorectal cancer. Prec. Radiat. Oncol. 2017, 1, 27-33. [CrossRef]

4. $\quad$ Ganesh, K.; Stadler, Z.K.; Cercek, A.; Mendelsohn, R.B.; Shia, J.; Segal, N.H.; Diaz, L.A., Jr. Immunotherapy in colorectal cancer: Rationale, challenges and potential. Nat. Rev. Gastroenterol. Hepatol. 2019, 16, 361-375. [CrossRef]

5. Andre, N.; Schmiegel, W. Chemoradiotherapy for colorectal cancer. Gut 2015, 54, 1194-1292. [CrossRef]

6. Wang, Y.; Deng, W.; Li, N.; Neri, S.; Sharma, A.; Jiang, W.; Lin, S.H. Combining immunotherapy and radiotherapy for cancer treatment: Current challenges and future directions. Front. Pharmacol. 2018, 9, 185. [CrossRef] 
7. Vaios, E.J.; Wo, J.Y. Proton beam radiotherapy for anal and rectal cancers. J. Gastrointest. Oncol. 2020, 11, 176-186. [CrossRef]

8. Matsuura, T.; Egashira, Y.; Nishio, T.; Matsumoto, Y.; Wada, M.; Koike, S.; Furusawa, Y.; Kohno, R.; Nishioka, S.; Kameoka, S.; et al. Apparent absence of a proton beam dose rate effect and possible differences in RBE between Bragg peak and plateau. Med. Phys. 2010, 37, 5376-5381. [CrossRef]

9. Habiba, K.; Aziz, K.; Sanders, K.; Santiago, C.M.; Mahedevan, L.S.K.; Makarov, V.; Weiner, B.R.; Morell, G.; Krishnan, S. Enhancing colorectal cancer radiation therapy efficacy using silver nanoprisms decorated with graphene as radiosensitizers. Sci. Rep. 2019, 9, 17120. [CrossRef]

10. Goswami, N.; Luo, Z.; Yuan, X.; Leong, D.T.; Xie, J. Engineering gold-based radiosensitizers for cancer radiotherapy. Mater. Horiz. 2017, 4, 817-831. [CrossRef]

11. Lan, M.; Zhao, S.; Liu, W.; Lee, S.-E.; Zhang, W.; Wang, P. Photosensitizers for photodynamic therapy. Adv. Healthc. Mater. 2019, 8, e1900132. [CrossRef]

12. Rashid, R.A.; Abidin, S.Z.; Anuar, M.A.K.; Tominaga, T.; Akasaka, H.; Sasaki, R.; Kie, K.; Razak, K.A.; Pham, B.T.T.; Hawkett, B.S.; et al. Radiosensitization effects and ROS generation by high Z metallic nanoparticles on human colon carcinoma cell (HCT116) irradiated under $150 \mathrm{MeV}$ proton beam. OpenNano 2019, 4, 100027. [CrossRef]

13. Wang, H.; Mu, X.; He, H.; Zhang, X.-D. Cancer radiosensitizers. Trends Pharmacol. Sci. 2018, 39, 24-48. [CrossRef] [PubMed]

14. Gill, M.R.; Vallis, K.A. Transition metal compounds as cancer radiosensitizers. Chem. Soc. Rev. 2019, 48, 540-557. [CrossRef] [PubMed]

15. Klebowski, B.; Depciuch, J.; Parlinska-Wojtan, M.; Baran, J. Application of noble metal-based nanoparticles in medicine. Int. J. Mol. Sci. 2018, 19, 4031. [CrossRef]

16. Bao, H.; Zhang, Q.; Xu, H.; Yan, Z. Effects of nanoparticles size on antitumor activity of 10-hydroxycamptothecin-conjugated gold nanoparticles: In vitro and in vivo studies. Int. J. Nanomed. 2016, 11, 929-940.

17. Anderson, D.S.; Sydor, M.J.; Fletcher, P.; Holian, A. Nanotechnology: The risks and benefits for medical diagnosis and treatment. J. Nanomed. Nanotechnol. 2016, 7, 4.

18. Borran, A.A.; Aghanejad, A.; Farajollahi, A.; Barar, J.; Omidi, Y. Gold nanoparticles for radiosensitizing and imaging of cancer cells. Radiat. Phys. Chem. 2018, 152, 137-144. [CrossRef]

19. Schlatholter, T.; Eustache, P.; Porcel, E.; Salado, D.; Stefancikova, L.; Tillement, O.; Lux, F.; Mowat, P.; Biegun, A.K.; van Goethem, M.-J.; et al. Improving proton therapy by metal-containing nanoparticles: Nanoscale insight. Int. J. Nanomed. 2016, 11, 1549-1556. [CrossRef]

20. Seo, S.-J.; Jeon, J.-K.; Han, S.-M.; Kim, J.-K. Reactive oxygen species-based measurement of the dependence of the Coulomb nanoradiator effect on proton energy and atomic Z value. Int. J. Radiat. Biol. 2017, 93, 1239-1247. [CrossRef]

21. Porcel, E.; Liehn, S.; Remita, H.; Usami, N.; Kobayashi, K.; Furusawa, Y.; Le Sech, C.; Lacombe, S. Platinum nanoparticles: A promising material for future cancer therapy? Nanotechnology 2020, 21, 85103. [CrossRef]

22. Peukert, D.; Kempson, I.; Douglass, M.; Bezak, E. Gold nanoparticles enhanced proton therapy: Monte Carlo modeling of reactive species distribution around gold nanoparticles and the effects of nanoparticle proximity and clustering. Int. J. Mol. Sci. 2019, 20, 4280. [CrossRef] [PubMed]

23. Torrisi, L. Gold nanoparticles enhancing protontherapy efficiency. Recent Pat. Nanotechnol. 2020, 9, 51-60. [CrossRef] [PubMed]

24. Li, S.; Bouchy, S.; Penninckx, S.; Marega, R.; Fichera, O.; Gallez, B.; Feron, O.; Martinive, P.; Heuskin, A.-C.; Michiels, C.; et al. Antibody-functionalized gold nanoparticles as tumor-targeting radiosensitizers for proton therapy. Nanomedicine 2019, 14, 317-333. [CrossRef] [PubMed]

25. Wang, W.; Chen, Q.; Jiang, C.; Yang, D.; Liu, X.; Xu, S. One-step synthesis of biocompatible gold nanoparticles using gallic acid in the presence of poly-(N-vinyl-2-pyrrolidone). Colloids Surf. A Physicochem. Eng. Asp. 2007, 1-3, 73-79. [CrossRef]

26. Lunkov, A.; Shagdarova, B.; Konovalova, M.; Zhuikova, Y.; Drozd, N.; Il'ina, A.; Varlamov, V. Synthesis of silver nanoparticles using gallic acid-conjugated chitosan derivatives. Carbohydr. Polym. 2020, 234, 115916. [CrossRef]

27. Li, D.; Liu, Z.; Yuan, Y.; Liu, Y.; Niu, F. Green synthesis of gallic acid-coated silver nanoparticles with high antimicrobial activity and low cytotoxicity into normal cells. Process Biochem. 2015, 50, 357-366. [CrossRef] 
28. Mittal, A.K.; Kumar, S.; Banerjee, U.C. Quercetin and gallic acid mediated synthesis of bimetallic (Ag-Se) nanoparticles and their antitumor and antimicrobial potential. J. Colloids Interface Sci. 2014, 431, 194-199. [CrossRef]

29. Naz, S.; Khasheli, A.R.; Aljabour, A.; Kara, H.; Talpur, F.N.; Sherazi, S.T.H.; Khasheli, A.A.; Jawaid, S. Synthesis of highly stable cobalt nanomaterial using gallic acid and its application in catalysis. Adv. Chem. 2014, 686925. [CrossRef]

30. Zhang, G.; Zheng, H.; Shen, M.; Wang, L.; Wang, X. Green synthesis and characterization of Au@Pt core-shell bimetallic nanoparticles using gallic acid. J. Phys. Chem. Solids 2015, 81, 79-875. [CrossRef]

31. Can, M. Green synthesis of Pd nanoparticles via gallic acid. Acta Phys. Pol. A 2017, 131, 569-571. [CrossRef]

32. Park, J.; Cha, S.-H.; Cho, S.; Park, Y. Green synthesis of gold and silver nanoparticles using gallic acid: Catalytic activity and conversion yield toward the 4-nitrophenol reduction reaction. J. Nanopart. Res. 2016, 18, 1665. [CrossRef]

33. Shan, F.; Zhang, X.-Y.; Fu, X.-C.; Zhang, L.-J.; Su, D.; Wang, S.-J.; Wu, J.-Y.; Zhang, T. Investigation of simultaneously existed Raman scattering enhancement and inhibiting fluorescence using surface modified gold nanostars as SERS probes. Sci. Rep. 2017, 7, 68135. [CrossRef] [PubMed]

34. Shim, K.; Lee, W.-C.; Heo, Y.-U.; Shahubuddin, M.; Park, M.-S.; Hossain, M.S.A.; Kim, J.H. Rationally designed bimetallic Au@Pt nanoparticles for glucose oxidation. Sci. Rep. 2018, 9, 894. [CrossRef] [PubMed]

35. Vetten, M.A.; Tlotleng, N.; Rascher, D.T.; Skepu, A.; Keter, F.K.; Boodhia, K.; Koekemoer, L.-A.; Andraos, C.; Tshikhudo, R.; Gulumian, M. Label-free in vitro toxicity and uptake assessment of citrate stabilized gold nanoparticles in three cell lines. Part. Fibre Toxicol. 2013, 10, 50. [CrossRef]

36. Gharibshahi, E.; Saion, E. Influence of dose on particle size and optical properties of colloidal platinum nanoparticles. Int. J. Mol. Sci. 2012, 13, 14723-14741. [CrossRef]

37. Luo, F.; Li, J.; Wu, S.; Wu, X.; Chen, M.; Zhong, X.; Liu, K. Comparative profiling between primary colorectal carcinomas and metastases identifies heterogeneity on drug resistance. Oncotarget 2016, 7, 63937-63949. [CrossRef]

38. Samari, F.; Parkhari, P.; Eftekhar, E.; Mohseni, F.; Yousefinejad, S. Antioxidant, cytotoxic and catalytic degradation efficiency of controllable phyto-synthesised silver nanoparticles with high stability using Corida myxa extract. J. Exp. Nanosci. 2019, 14, 141-159. [CrossRef]

39. Kutwin, M.; Sawosz, E.; Jaworski, S.; Wierzbicki, M.; Strojny, B.; Grodzik, M.; Sosnowska, M.E.; Trzaskowski, M.; Chwalibog, A. Nanocomplexes of graphene oxide and platinum nanoparticles against colorectal cancer Colo205, HT-29, HCT-116, SW480, liver cancer HepG2, human breast cancer MCF-7, and adenocarcinoma LNCaP and human cervical Hela B cell lines. Materials 2019, 12, 909. [CrossRef]

40. Park, M.V.D.Z.; Neigh, A.M.; Vermeulen, J.P.; de la Fonteyne, L.J.J.; Verharen, H.W.; Briede, J.J.; van Loveren, H.; de Jong, W.H. The effect of particle size on the cytotoxicity, inflammation, developmental toxicity and genotoxicity of silver nanoparticles. Biomaterials 2011, 32, 9810-9817. [CrossRef]

41. Sukhanova, A.; Bozrova, S.; Sokolov, P.; Berestovoy, M.; Karaulov, A.; Nabiev, I. Dependence of nanoparticles toxicity on their physical and chemical properties. Nanoscale. Res. Lett. 2018, 13, 44. [CrossRef]

42. Baskar, R.; Dai, J.; Wenlong, N.; Yeo, R.; Yeoh, K.-W. Biological response of cancer cells to radiation treatment. Front. Mol. Biosci. 2014, 1, 24. [CrossRef] [PubMed]

43. Li, Y.; Yun, K.-H.; Lee, H.; Goh, S.-H.; Suh, Y.-G.; Choi, Y. Porous platinum nanoparticles as a high-Z and oxygen generating nanozyme for enhanced radiotherapy in vivo. Biomaterials 2019, 197, 12-19. [CrossRef] [PubMed]

44. Chowdhury, S.; Ongchin, M.; Sharratt, E.; Dominguez, I.; Wang, J.; Brattain, M.G. Intra-tumoral heterogeneity in metastatic potential and survival signaling between iso-clonal HCT116 and HCT116b human colon carcinoma cell lines. PLoS ONE 2013, 8, e60299. [CrossRef] [PubMed]

45. Gnosa, S.; Capodanno, A.; Murthy, R.V.; Jensen, L.D.E.; Sun, X.-F. AEG-1 knockdown in colon cancer cell lines inhibits radiation-enhanced migration and invasion in vitro and in a novel in vivo zebrafish model. Oncotarget 2016, 7, 81634-81644. [CrossRef]

46. Kim, S.-H.; Jun, C.-D.; Suk, K.; Choi, B.-J.; Lim, H.; Park, S.; Lee, S.H.; Shin, H.-Y.; Kim, D.-K.; Shin, T.-Y. Gallic acid inhibits histamine release and pro-inflammatory production in mast cells. Toxicol. Sci. 2016, 91, 123-131. [CrossRef]

47. Borges, A.; Ferreira, C.; Saavedra, M.J.; Simoes, M. Antibacterial activity and mode of action of ferulic and gallic acids against pathogenis bacteria. Microb. Drug Resist. 2013, 19, 256-265. [CrossRef] 
48. Sun, G.; Zhang, S.; Xie, Y.; Zhang, Z.; Zhao, W. Gallic acid as a selective anticancer agent that induces apoptosis in SMMC-7721 human hepatocellular carcinoma cells. Oncol. Lett. 2016, 11, 150-158. [CrossRef]

49. Liu, Z.; Li, D.; Yu, L.; Niu, F. Gallic acid as a cancer-selective agent induces apoptosis in pancreatic cancer cells. Chemotherapy 2012, 58, 185-194. [CrossRef]

50. Aborehab, N.M.; Osama, W. Effect of gallic acid in potentiating chemotherapeutic effect of paclitaxel in HeLa cervical cancer cells. Cancer Cell Int. 2019, 19, 154. [CrossRef]

51. Jiang, Y.; Wong, S.; Chen, F.; Chang, T.; Lu, H.; Stenzel, M.D. Influencing selectivity to cancer cells with mixed nanoparticles from albumin-polymer conjugates and block biopolymers. Bioconjugate Chem. 2017, 28, 979-985. [CrossRef]

52. Bazak, R.; Houri, M.; El Achy, S.; Kamel, S.; Refaat, T. Cancer active targeting by nanoparticles: A comprehensive review of literature. J. Cancer Res. Clin. Oncol. 2015, 141, 769-784. [CrossRef] [PubMed]

Publisher's Note: MDPI stays neutral with regard to jurisdictional claims in published maps and institutional affiliations.

(C) 2020 by the authors. Licensee MDPI, Basel, Switzerland. This article is an open access article distributed under the terms and conditions of the Creative Commons Attribution (CC BY) license (http://creativecommons.org/licenses/by/4.0/). 